\title{
Cracking the humanitarian logistic coordination challenge: lessons from the urban search and rescue community
}

Peter Tatham, Professor of Humanitarian Logistics, Department of International Business and Asian Studies, Griffith Business School, Gold Coast, Australia, and Karen Spens, Rektor, Hanken School of Economics, Helsinki, Finland

The challenges of achieving successful inter-agency logistic coordination in preparing for, and responding to, natural disasters and complex emergencies are both well understood and well documented. However, although many of these challenges remain unresolved, the literature reveals that the organisations that form the urban search and rescue (USAR) community have attained a high level of coherence and interoperability that results in a highly efficient and effective response. Therefore, this paper uses the idea of 'borrowing' from other fields as it explores how the processes and procedures used by the USAR community might be applied to improve humanitarian logistic operations. The paper analyses the USAR model and explores how the resultant challenges might be addressed in a humanitarian logistic context. The paper recommends that further research be undertaken in order to develop an modified USAR model that could be operationalised by the international community of humanitarian logisticians.

\section{Keywords:}

Humanitarian Logistics; Urban Search and Rescue; Foreign Medical Teams; InterAgency Coordination;

\section{Introduction}

Humanitarian logistics (HL), the logistic component of preparing for and responding to natural disasters and complex emergencies, is a broad field that encompasses the management of the entire supply network. This breadth of responsibility is reflected in the common definition of HL: 'The process of planning, implementing and controlling the efficient, cost-effective flow and storage of goods and materials as well as related information, from the point of origin to the point of consumption for the purpose of meeting the end beneficiary's requirements' (Thomas and Mizushima, 2005, p. 60). 
Therefore, almost every agency, be it national, international, governmental, United Nations (UN), non-governmental, Red Cross/Crescent or military that is involved in disaster/emergency preparation and response activities, is likely to be engaged in some form of logistic activity. Indeed, it has been estimated that some 60 to 80 per cent of the expenditure of relief agencies is spent on HL, and that this can be translated into a global figure of around USD 10 billion to USSD 15 billion per year (Tatham and Pettit, 2010). Furthermore, the advent of a major disaster results in multiple responding entities-for example, more than 400 organisations and 5,000 members of staff were registered by the UN in Banda Aceh (Indonesia) in the aftermath of the 2004 tsunami (Völz, 2005). Therefore, it is argued that one of the ways in which HL efficiency and effectiveness can be improved is through the development of improved inter-agency coordination mechanisms.

\section{Aim}

Logisticians are not the only professionals working in the disaster response space, and the authors are mindful of Stock's (1997) recommendation that logistics, as an emerging field of study, should 'borrow' from other disciplines as a means of advancing knowledge and understanding. In this paper the core idea is to borrow from other areas in order to improve operations in the HL field and its aim is, therefore, to explore the processes and procedures used in the USAR community and to discuss how their approach might be applied to improve the operation of HL agencies.

More specifically, the paper adds to the coordination literature by exploring the organisational approaches and constructs of the USARs - as well of those of the Foreign Medical Teams (FMTs) (another emerging inter-agency grouping) - in order to understand their strengths and weaknesses, as well as the barriers to the implementation of a similar construct within the humanitarian logistic community.

It is stressed that although the research is conceptual in nature, it has been developed through a broad ranging literature review that was designed to surface the key issues in relation to the three communities in question (USAR, FMT and HL). For this purpose, a number of key sources were analysed including the major journals within the field: Disasters, Disaster Prevention and Management (DPM), International Journal of Mass Emergencies and Disasters (IJMED), Journal of Contingencies and Crisis Management (JCCM) and Journal of Humanitarian 
Logistics and Supply Chain Management (JHLSCM). A number of other journals that have recently run special editions relating to this topic were also analysed, including Management Research News and International Journal of Physical Distribution and Logistics Management. To this analysis was added the practitioner sources such as the websites of the US Federal Emergency Management System (FEMA) and its National Incident Management System (NIMS), and the equivalent system in the United Kingdom - the Integrated Emergency Management (IEM) structure. The resulting draft paper was then presented to, and discussed with, key personnel who are based in Australia, Europe and the United Kingdom, and amendments were made to reflect their observations. These discussants comprised: (a) seven humanitarian logisticians (who are members of UN, non-governmental organisations and Red Cross agencies); (b) two staff involved in the development of the FMT concept of operations; and (c) one member of a national search and rescue organisation who acts as a mentor for other national groupings.

The paper will first offer a review of the literature relating to interorganisational coordination in a disaster response context. It will then provide an overview of USAR, FMT and HL communities before offering an analysis of the core organisational and inter-organisational constructs of USAR/FMTs. A discussion on how these might be applied to improve the operation of HL agencies is then provided, after which a number of recommendations for further research are offered.

\section{An overview of the coordination challenge}

The literature review demonstrated that the challenges associated with inter-agency coordination in the preparation for, and response to, disasters/emergencies have been discussed widely within the literature from a number of perspectives. Thus, Smith and Elliott (2007) reflect on the barriers to organisational learning and the limited consideration that has been given to these, whilst Kapucu et al. (2010) reflect on the potential benefits of mechanisms that enable individual organisations to fulfil their particular role and remit while, simultaneously, contributing to the macro-level response. Conversely, Berlin and Carlström (2011) study the underpinning reasons why such inter-agency coordination is minimised at accident scenes and, in doing so, expose the differences between rhetoric and practice in a Swedish context. In the same vein, Salmon et al. (2011) discuss the particular challenge of coordination 
between civil and military organisations and emphasise the importance of leadership, a clear understanding of the roles and responsibilities of the various agencies and of inter-agency information management and exchange.

The resultant analysis indicates that there are two basic models that reflect the presence (or absence) of a central player with the authority to direct the entire relief operation - approaches described by Dolinskaya et al. (2011) as 'centralised' versus 'decentralised'. Importantly the literature, in particular that related to the domestic environment in which the efforts of various organisations (typically fire, police, ambulance and military forces) are overseen by a unitary command authority, is almost entirely focused on the challenges inherent in centralised models - see, for example, the Integrated Emergency Management (IEM) structure described by Salmon et al. (2011). By comparison, Clarke (2013) points out that while the coordination of programming and policy has been much debated at national, intergovernmental and academic levels, post-crisis and transitional coordination structures have remained weak, particularly at the field level-a situation that is reflected in the unintegrated and frequently incoherent logistic activities of the multiple agencies that respond to a rapid onset disaster (Tatham and Pettit, 2010).

Turning to the HL literature, it is relevant to note its relative paucity. Thus, a recent analysis by Kunz and Reiner (2012) uncovered just 174 published papers in the period 1995-2011, of which 118 had been published in the last three years of their research window. Unsurprisingly, the early years of an emerging field reflect the need to develop a common understanding of the core concepts, their inter-relationships and the vocabulary and its meanings. One such set of concepts are cooperation, collaboration, coordination and integration (for example, Day et al., 2012; Kovács and Spens, 2009; Oloruntoba and Gray, 2009), which are often used interchangeably both outside the humanitarian context as well as within it (Jahre and Jensen, 2010). This focus on coordination is also evident in practice, and the most prominent coordination mechanism is the one developed across the UN family of agencies under the 'cluster' concept. Using this approach, a broad range of preparation and response activities are grouped together into clusters (for example, water and sanitation; camp management; emergency telecommunications) with the logistics cluster being led by the World Food Programme (WFP) (IASC, 2012). Importantly: 
no formal membership definition exists as the [logistics] cluster has sought to remain open and not exclusive. Rather, Logistics Cluster participants are defined as organisations 'engaging at any point at global and/or country level in activities related to the Logistics Cluster' (Majewski et al., 2012, p. 6).

Nevertheless, and notwithstanding the UN's aspiration that the cluster system becomes the basis for coordination across the sector as a whole, the reality is that most humanitarian agencies (HAs) maintain a considerable degree of independence and only interface with the UN Logistic Cluster when the particular circumstances of the disaster response make this, in their eyes, the optimal course of action. In short, whilst the HL literature contains multiple examples in which inter-agency coordination is seen to be a key challenge, there is limited coverage of mechanisms for overcoming this key issue.

However, literature also reveals one successful initiative, namely the USAR community, which, by common consent, has attained a high level of coherence and interoperability resulting in a highly efficient and effective response. Given that, at a strategic level, both the HL and USAR communities are engaged in the broadly similar activity of delivering external assistance to a country that has been affected by a disaster beyond its ability to manage, the question posed is why a similar mechanism to that which already exists within the USAR community (and which is emerging amongst the FMTs) should and/or could not be adopted by those working in the HL context.

With the above discussion in mind, the USAR and FMT organisational constructs were chosen as exemplars that had the potential to inform the HL coordination challenge due to their co-existence in multiple disaster/emergency events but, in doing so, the core centralised-versus-decentralised distinction was firmly recognised. To take this review forward, the next sections will briefly introduce the USAR and FMTs, after which an analysis of the potential cross-learning lessons will be undertaken.

\section{INSARAG}

The International Search and Rescue Group (INSARAG) guidelines and methodology (INSARAG, 2012) provide a coherent and proven coordination mechanism for the 
preparation and response of multiple USAR teams. INSARAG consists of a global network of more than 80 countries and it aims to establish a common methodology for international coordination in response to earthquakes and similar disasters, together with an associated set of minimum international standards for USAR teams. It is supported by a secretariat that forms part of the Emergency Services Branch (ESB) of the UN Office for the Coordination of Humanitarian Affairs (UN OCHA) in Geneva.

\section{The INSARAG organisational model}

Figure 1 gives an overview of the high level organisational construct for INSARAG, within which the steering group consists of the chairperson, the secretary (who is the chief of the field coordination support section (FCSS) of UN OCHA), the chair and deputy chair of each of the regional groups and of any ad hoc working groups, and a representative of the International Federation of the Red Cross and Red Crescent Societies (IFRC). It will be appreciated, therefore, that INSARAG, while not being a UN agency as such, has very close links to, and support from, the United Nations.

Figure 1. The INSARAG structure

Source: INSARAG (2012, p. 12) with permission.

\section{The INSARAG guidelines}

Key to the success of the INSARAG approach has been the development of a comprehensive set of guidelines (INSARAG, 2012) that cover the whole spectrum of the disaster response cycle with sections covering:

- preparedness: including training and the investigation of lessons identified in previous operations, and any consequential amendments to standard operating procedures (SOPs);

- mobilisation: the actions required by all parties following the occurrence of a disaster; 
- operations: the actual operating procedures, including those relating to the Reception/Departure Centre (RDC) and the On Site Operations Coordination Centre (OSOCC), as well as issues to be considered in ensuring that the response is ethically based and sensitively delivered;

- demobilisation: the actions required on the completion of a USAR operation;

- post-mission: the actions that relate to the submission of a post-mission report and the identification of lessons to improve future operations.

Importantly, the guidelines clearly indicate the actions required by the three key groups of stakeholders - the affected country, the assisting country and the international USAR teams. Equally importantly, and accepting that they are not mandatory for any of the parties, the guidelines have been developed over some 25 years and represent a clear exposition of best practice. Thus they form the baseline/default position that can be modified as necessary in light of the particular disaster circumstances.

\section{Qualifications, standards and certification}

The guidelines clearly recognise that USARs will have different capabilities, and this is operationalised through a classification of light, medium and heavy teams (INSARAG, 2012, pp. 33-34). This, in turn, has led to a clear statement of the minimum capabilities required of a USAR team at each classification level, which includes the requirements for team management, logistics, search, rescue, medical staff and equipment. The capabilities of the USARs are monitored through a system of external classification that helps to ensure the appropriate standards are developed and maintained. This process incorporates mentoring from a suitable qualified senior team leader, and a formal examination of the USAR capabilities that is undertaken by an external team. This approach has also led directly to a set of individual and team training requirements that are documented in the guidelines. It should be noted in passing that for national USAR organisations, achievement of a 'heavy' INSARAG classification is greatly prized. 
Given the importance of speed in the deployment of USAR teams, the operational focal points within each assisting country (which, under the INSARAG guidelines, are required to operate 24/7) are linked in to the UN/European Union (EU) Global Disaster Alert and Coordination System (GDACS). This provides the international disaster response community with near real-time alerts about natural disasters around the world, as well as tools to facilitate response coordination (GDACS, 2013). USARs that are invited to respond must do so within the guideline times - thus a medium USAR team should be operational in the affected country within 32 hours of notification of the disaster incident, and a heavy USAR team should be operational in country within 48 hours.

The INSARAG guidelines also specify that, as part of the overall operational coordination, a RDC should be established at points of entry into an affected country (for example airports). The aim of the RDC is to work in close cooperation with immigration, customs and other local authorities thereby facilitating the arrival (and, subsequently, the departure) of the USARs. Whilst the RDC will normally be manned by staff from UN OCHA in the form of a United Nations Disaster Assessment and Coordination (UNDAC) team, in the event that a USAR arrives at the point of entry ahead of the UNDAC, the guidelines specify that the first USAR team should man the RDC until UNDAC staff arrive to take over this responsibility - as indeed was the case in the 2010 Haiti earthquake where the UK USAR manned the RDC at Santa Domingo airport for the first 48 hours of the response (SARAID, 2010). Thus, countries are encouraged to incorporate the establishment, staffing and operation of a RDC into their disaster preparedness plans, and this capability is tested during USAR classification evaluations.

Under the guidelines, the OSOCC is established as close to the disaster site as is safely possible. It provides a platform for the coordination of international responders and affected country's emergency management authority, as well as establishing inter-cluster coordination mechanisms (for example, with and between health, water/sanitation, shelter). As in the case of the RDC, the OSOCC is established by the UNDAC team or by the first arriving international USAR team, which will then hand over responsibility to the UNDAC team when it arrives. The final element of the management and coordination mechanism is the virtual OSOCC (VO), which is a web-based information portal managed by UN OCHA. It is designed 
to facilitate information exchange between responders and the affected country after sudden onset disasters.

In summary, over a period of some 25 years, a robust coordination mechanism has been developed that enables trained and equipped USAR teams to respond quickly to a rapid onset disaster through mechanisms that maximise the commonality of approach and, hence, the ability of the USARs to cooperate both with the local authorities and their USAR colleagues.

\section{FMT}

With the aim of helping to regulate the activities of FMTs, the World Health Organisation (WHO) and the Pan-American Health Organization (PAHO) first produced a set of guidelines in 2003. However, it is generally considered that adherence to these has been limited (von Schreeb et al., 2008). The experience of the uncoordinated influx of medical personnel in recent disasters such as the 2010 Haiti earthquake proved the catalyst for a revision of the original PAHO guidelines. This has been overseen by the UN Inter Agency Standing Committee (IASC) Global Health Cluster FMT Working Group (IASC, 2011), and has led to the publication of the core document: Classification and Minimum Standards for Foreign Medical Teams in Sudden Onset Disasters (Norton et al., 2013). Importantly, these guidelines have been developed with the cooperation of more than 30 non-governmental organisation (NGO) stakeholders who are Global Health Cluster Partners (GHC, 2013) and have, thus, successfully bridged the potentially contentious UN/NGO interface.

Equally importantly, the FMT guidelines fully acknowledge that there are important similarities between the FMT and USAR contexts, including that both:

- are directed at the sending and receiving countries, as well as the responding organisations and team members;

- are designed to achieve greater clarity and understanding at all governmental levels and, hence, aim to deliver improved response coordination and standards;

- enhance the preparedness of both the sending and receiving countries; 
- $\quad$ seek to clearly define the capabilities of a responding entity.

However, the two cases (USAR and FMTs) also exhibit some significant differences, which include:

- the broader mix of actors in a health context, and consequential increase in complexity of the preparation and response activities;

- the longer period of deployment of FMTs (three to four weeks) when compared to the USARs, where the response is usually completed in some 10 to 14 days;

- the changing nature of the medical needs over the period of an FMT deployment;

- the number of beneficiaries (thousands of injured and millions of displaced) that are potential patients of an FMT compared with the one to five per cent of survivors trapped in the aftermath of a rapid onset disaster.

Nevertheless, as emphasised by Norton et al. (2013), the general approach adopted in FMT guidelines deliberately mirrors that of INSARAG. Thus, for example, the intention is that FMTs should utilise a similar RDC mechanism as well as placing the FMT coordination cells under the control of the OSOCC.

Importantly, one of the key requirements for certification is that the FMT will commit to international standards of performance both in a medical context, as well as in a procedural sense (that is, adherence to common processes such as the RDC and OSOCC). On the other hand, in the first instance, the FMTs would operate under a system of self (as distinct from external) classification that will indicate the range and complexity of care that is within the capacity and capability of an individual FMT. For the future, however, alternative quality assurance measures will be explored, including a peer reviewed external classification system similar to that operated by INSARAG (FMTWG, 2013).

In summary, the FMT guidelines are designed to overcome historic issues whereby international medical teams have responded to disasters with the best of 
intentions, but in some cases have lacked the experience and/or logistic support that were required. Furthermore, the absence of a common lexicon for classifying FMTs has hampered the host nation's ability to deploy the teams to best effect in light of their particular capabilities.

\section{The challenges of applying the INSARAG/USAR model to HL}

In the following section, the INSARAG/USAR model will be used as the main comparator given its relative stability as an organisational construct, and its comparative longevity (some 25 years). Table 1 is designed to outline some of the key differences between the INSARAG/USAR and HL communities, with the following example being offered as an expansion of the issue raised in the first entry of the table.

The context of the disaster environment may have a significant degree of commonality - such as devastated physical and communications infrastructure; multiple dead and injured people, potential breakdown of the rule of law; national and international exposure in multiple forms of media (Kovács and Tatham, 2009) however, those preparing and responding have a considerable divergence of backgrounds. In the case of international USARs, the individuals typically belong to national fire and emergency services, but have additional training to enable them to meet the individual and collective INSARAG requirements and, thereby, be accredited for international deployment. By the same token, the necessary equipment will normally have been procured for domestic use, but is available to be deployed as part of a USAR team. By contrast, whilst those providing humanitarian logistic services may well have some background and experience, there is only a limited career path within this field and an acknowledged high turnover of staff (Thomas and Kopczak, 2005).

Furthermore, although the majority of USAR organisations that have INSARAG certification are directly linked to their home government (for example, their personnel are members of national fire and rescue services), this is not universally true. Thus, five out of the 34 INSARAG certified teams (15 per cent) are actually operated by NGOs, and so a key observation is that, in a similar way to the FMTs, INSARAG has managed to bridge the UN/NGO boundary, which has been a 
considerable challenge to attempts to achieve improved coordination in the logistic field (Glad, 2011).

Table 1. Comparison of international USAR and HL responses.

\begin{tabular}{|c|c|}
\hline INSARAG/USAR scenario & UN/NGO/IFRC scenario \\
\hline $\begin{array}{l}\text { The staff manning the USAR are employed in } \\
\text { a similar role in a domestic context to that } \\
\text { which they would employ if deployed } \\
\text { internationally. }\end{array}$ & $\begin{array}{l}\text { This is partially true for the UN/NGO } \\
\text { community, although a disaster of any } \\
\text { magnitude requires the short notice } \\
\text { recruitment of additional staff who may not } \\
\text { have experience of operating in a disaster } \\
\text { response environment. }\end{array}$ \\
\hline $\begin{array}{l}\text { The staff manning the USAR are, typically, } \\
\text { in continuing employment and, as such, are } \\
\text { part of a regime of individual and collective } \\
\text { training, development and certification. }\end{array}$ & $\begin{array}{l}\text { Core NGO staff may be in continuing } \\
\text { employment, but significant use is made of } \\
\text { both contract personnel and, in the case of } \\
\text { major rapid onset disasters, short-term } \\
\text { supernumerary appointments. }\end{array}$ \\
\hline $\begin{array}{l}\text { The necessary equipment has been procured } \\
\text { and is therefore ready for deployment } \\
\text { nationally or internationally as required. }\end{array}$ & $\begin{array}{l}\text { The HL response typically relies to a } \\
\text { significant extent on the local procurement of } \\
\text { personnel, trucks and warehouses. }\end{array}$ \\
\hline $\begin{array}{l}\text { Under the INSARAG Guidelines } \\
\text { international USAR teams must be self- } \\
\text { sustaining (e.g. with equipment, food, water, } \\
\text { medicines, accommodation) for seven days } \\
\text { (medium teams) and ten days (heavy teams), } \\
\text { and are required not to import or use locally } \\
\text { procured stores for consumption by } \\
\text { individuals who are part of the team. }\end{array}$ & $\begin{array}{l}\text { There is generally no such requirement for } \\
\text { HL teams to be self-sufficient, not least as } \\
\text { they are likely to be deployed for longer } \\
\text { periods than the INSARAG teams. }\end{array}$ \\
\hline $\begin{array}{l}\text { The costs of preparation, training, } \\
\text { deployment and operation are born by the } \\
\text { assisting country, including those related to } \\
\text { capacity building such as exchanges of staff, } \\
\text { attendance at conferences. }\end{array}$ & $\begin{array}{l}\text { The equivalent costs must be raised through } \\
\text { donations from governments or the public } \\
\text { leading, potentially, to competition between } \\
\text { agencies/NGOs. }\end{array}$ \\
\hline The USAR will, typically, not remain in the & The HL teams are likely to remain in country \\
\hline
\end{tabular}


affected country beyond some 14 days after

for many weeks/months, or even years.

the disaster has struck.

The benefits of the INSARAG model

Summarising the above discussion, the broader question is whether adoption of the high level INSARAG construct would achieve an improved (that is, more effective/efficient) logistic outcome? The following are perceived to be the basic building blocks of the INSARAG approach which, as it will be clearly seen, reflects the centralised model of Dolinskaya et al. (2011):

- A set of common guidelines, which, although by definition offering guidance rather than prescription, provide a framework and associated SOPs that are employed by multiple organisations (be these nationally funded or NGOs) from multiple countries. This greatly eases interoperability issues and helps ensure that the OSOCC can make valid assumptions as to USAR modus operandi.

- A common training and certification regime in which the capabilities of applicant organisations are externally assessed.

- A common alert system (GDACS) and associated management overview (the VO) that provide overall high level coordination of the operational response to the disaster.

- Standardised reception and departure procedures controlled through the RDC.

- A hierarchical leadership/command and control structure that, although not prescriptive in nature, provides an operating framework is generally adhered to by individual USARs. The OSOCC is, thus, able to allocate operational sectors to USARs according to their capability and the type and extent of the damage, potential for life saving actions, and so on.

- Common information management processes that support the work of the OSOCC. 
- A secretariat that provides a broad range of support services such as maintenance of the website, administration of meetings and custody of the process for identifying lessons after each operational deployment.

Furthermore, as indicated above, while the processes are less mature, the emerging FMT guidelines appear to be aiming to achieve a similar organisational constructalbeit, as discussed earlier, there is a greater complexity in the provision of medical support as well a need for longer duration deployments during which the population's needs will change.

\section{The challenges to the adoption of the INSARAG model within the HL community}

If one accepts the benefits of the above building blocks in delivering an efficient and effective response and that their application in the HL context would achieve similar improvements, what then are the key barriers to the implementation of a similar INSARAG-like model?

The first point to recognise when considering the adoption of the INSARAG model in the HL context is that the two scenarios are not parallel. Thus, as discussed above, the maximum duration of an INSARAG deployment is of the order of two weeks. As a result, the actions of the INSARAG teams tend to reflect Gattorna's concept of 'full flexibility', which the author describes in the following terms: 'Fully flexible supply chains - wherever they occur - are designed to find a solution, and find it very fast. If this requires creative thinking, innovative behaviour, intense flexibility, and high costs, then so be it. The final result is paramount' (Gattorna, 2010 , p. 252, emphasis in original). However, as one moves out of this rapid onset context, the more efficiency (as distinct from effectiveness) becomes important and, hence, operations are increasingly required to conform to a particular rule set.

Second, the generic approach that has been adopted by the INSARAG community clearly reflects a hierarchy that is overseen by a unitary decision maker (or, in some cases, a group of senior decision makers). A similar approach has been adopted within the FMTs, where Aitken et al. (2012, p. 144) note that 'public health emergency management is not a democratic process'. Rather, these authors highlight the results of a survey of medical disaster assistance teams in which the respondents stressed the importance of having one individual in charge of an emergency response 
and that this individual should be able 'to make appropriate decisions quickly, and often on the basis of incomplete or uncertain data' (Aitken et al., 2012, p. 144).

Interestingly, Aitken et al. (2012) note that this style of leadership does not reflect the normal collaborative approach found in the health context and is more aligned to that found in a police, military or fire fighting context. It is also relevant that such a hierarchical command structure is generally not found within the HL communities where flatter organisational constructs are more prevalent. However, as noted by one USAR practitioner, given that NGOs have never operated in such a hierarchical 'command' structure, they may not be aware of the benefits that it might bring.

The next challenge relates to the linkage between INSARAG and UN OCHA (and the similar arrangements for the FMTs in respect of the WHO). On the one hand, there is a clear belief within some NGOs that the political nature of the UN does not fully reflect the core values of humanity, impartiality, neutrality and independence. Thus there is a reluctance to engage too closely with UN entities. On the other hand, it is clear that NGO organisations taking part in USAR/FMT operations appear to have accepted the necessity of engaging with the relevant UN agency. Importantly in this respect, the UN Logistics Cluster has emphasised its open nature and, indeed, there is clear evidence of increasing engagement between the Logs Cluster and the NGO community at large. For example, some 75 NGOs used the (free at the point of use) cluster-operated trucking service from Santa Domingo to Port-au-Prince during the 2010 Haiti earthquake (Logistics Cluster, 2010).

Nevertheless, the reality is that a model of total UN/NGO cooperation would appear to be somewhat distant. An alternative approach might be one in which a number of NGOs agree to cooperate on a voluntary basis and develop, to steal a military metaphor, 'a coalition of the willing'. To be successful, however, this would be greatly simplified, and hence more achievable, if underpinned by a greater commonality in the operational components such as common training regimes, common capability standards, common commodity catalogues and common IT systems and associated processes. Importantly, this does not necessarily imply standardisation of processes - rather, a common approach that leads to a relative ease of interoperability. As an example, it is understood that members of the UN's water and sanitation (WATSAN) cluster (including the relevant NGOs) have recently agreed a common set of technical standards for materials (for example, pipework 
sizes and connection design) so that, whatever the source, the equipment is interoperable (de Leeuw et al., 2010).

The benefits of such commonality are frequently accepted by those operating at the field level, but the very real challenge remains the cost of achieving the necessary process changes as well as the reluctance at the policy level to sacrifice the prized independence of action. Nevertheless, if the arguments for this approach can be substantiated, there would appear to be a very real opportunity for the funding organisations to influence the debate through, for example, making future funding conditional on implementation of a similar model to the INSARAG approach.

In the medical context, it has been argued by Aitken et al. (2012) that failure to achieve an integrated response may lead to death of patients, a lack of adequate medical supplies, and staff working beyond their training or certification. This observation clearly links into the current debate over the need for improved standards and the associated certification processes within the HL community at large. In relation to the former, the development of an improved humanitarian standards architecture is being championed through the Joint Standards Initiative (JSI) which has the full backing of the three most influential bodies in this context: the Humanity Accountability Partnership, People in Aid and The Sphere Project (Austin and O’Neill, 2013).

Importantly, the first stages of the JSI work have clearly highlighted one obvious implication of their work which is that standards in themselves have only a limited value unless they are supported by a system of compliance and verification. However their consultation to date has not produced any consensus on how this might be achieved, although the debate seems to be leaning towards a system of internal assessment with external peer review and audit (Austin and O'Neill, 2013, p. xii). On the face of it, such a model would appear to be positioned part way between the INSARAG external assessment and the FMT's self-certification processes.

Within the HL community itself, there would seem to be an increasing demand for some form of certification. For example, the proceedings of the annual Fritz Institute sponsored Humanitarian Logistics Conference in 2012 notes that 'Participants repeated the call to instil sector-wide competencies and standard language, and provide recognized training', and in the subsequent break-out sessions that 'A certification process for Humanitarian Logistics is required' (Fritz Institute, 2012). This, in turn, clearly links into the work of the Steering Committee for 
Humanitarian Response (SCHR), which, in early 2013, launched a two year project to explore the question of whether certification of humanitarian organisations could contribute to greater programme quality and accountability to the affected populations and other stakeholders (SCHR, 2013).

Clearly there are two intertwined issues here: that of the certification of organisations and that of individuals. While the debate has yet to play out, and indeed this thorny issue has surfaced on a number of occasions during the 20th century, it is interesting to note that the experience of the INSARAG model shows that such certification at an organisational level is an essential component, and this would appear to be the route that is being followed by the FMTs. Within this, individual USAR groups/FMTs must decide what capabilities an individual team member must possess and how these should be assessed/validated. Clearly different models may apply: for example, it may well be appropriate to use internal assessment at the individual level, and external assessment for organisations. Nevertheless, putting the actual modalities to one side, it is suggested that the benefits of certification at both the organisational and individual level have yet to be countered and, further, that the HL community as a whole is moving in this direction - a route that has clear implications for the importance of professionalisation within the field which is (yet) another subject of current debate, albeit in terms of how (rather than why) it can be achieved.

Finally, and notwithstanding considerable impetus driven by the donor organisations that are keen to understand how efficiently/effectively their funds have been spent, robust measurement of the impact of any disaster response and the associated cost effectiveness remains a clear measurement challenge (Tatham and Hughes, 2011). Overall, there is a paucity of available standards, benchmarks and indices, the absence of which makes both assessment and the ability to learn from experience more difficult. This lack of standards extends to training with, at present, no clear way to assess the abilities and competencies of the organisations and people who volunteer to help an affected population. While many organisations are working to overcome this challenge-for example, the work of the World Food Programme's development of supply chain metrics (WFP, 2012) - it was noted in the discussion at the 2012 Humanitarian Logistics Conference that further work is needed to develop simple, universal Key Performance Indicators (KPIs) (Fritz Institute, 2012). Self- 
evidently, there is a link between the development of such KPIs and the development of standards and certification discussed above.

\section{Summary and further research}

Coordination and integration is a challenge and concern for many actors in the humanitarian logistics field. Even though there are a number of measures that have been developed in order to improve coordination (for example, the use of the cluster approach), it is evident that there remains a need to improve coordination in order to improve the efficiency and effectiveness of disaster response. In a recent paper (Tatham et al., 2013), the authors suggest that the use of a common humanitarian logistics picture could be a partial response to the humanitarian logistics coordination challenge. Through this mechanism, the ultimate goal is to provide those engaged in the delivery of logistic support in the aftermath of a disaster or emergency with a near real-time shared awareness of the current and emerging response-in other words, a model that is broadly similar to the OSOCC described above.

Subsequent implementation of this vision would improve the ability of decision makers to react to the unfolding circumstances in a timely, efficient and effective way. In a recent study, Akhtar et al. (2012) identify chain coordinators and explore their roles, the specific competencies of the coordinators, and challenges in the coordination through a case study of the 2005 South Asian earthquake. They offer a list of assets, which they argue are key determinants for supply chain coordination success, tangible (finance, technology and people) and intangible (leadership, extra efforts, relevant experiences and education, relationship management skills, research abilities and performance measurement skills). In a similar fashion, Clarke (2013) puts forward a list of principles for successful transitional coordination and discusses two key issues, namely the importance of a coordination structure that promotes the use of regional sub-offices, and the importance of an inclusive planning process.

The aim of this paper was to explore the processes and procedures used in the USAR community to discuss how the lessons learned might be applied to improve the operation of HL agencies. This paper thereby adds to the coordination literature by exploring the organisational approaches and constructs of INSARAG/USAR and the FMTs in order to understand both their strengths and weaknesses, as well as the barriers to the implementation of a similar construct within the HL community. 
Although this paper has been developed at a conceptual level, it has been discussed with a number of key informants from the international HL, USAR and FMT practitioner communities. The study is, however, limited in terms of the number of informants and more research, for example via a thorough empirical study, is needed in order to corroborate the initial findings.

Nevertheless, the findings indicate that there is a clear measure of agreement over the practical implications of improved coordination. But the major sticking point remains the determination of NGOs to maintain their independence and, thereby, to operate within the terms of their organisation's mandate in ways that they believe to be most appropriate. With this in mind, it is clear that-short of a major change of heart amongst key NGO players - a direct clone of the INSARAG/FMT approach, even one outside the UN, is unlikely to come into effect. However, at a level below that of a pan-sector change of approach, there was general support for continued research to quantify the costs and benefits of the development of a greater level of coordination along the lines of INSARAG (that is, development of a common set of guidelines, training syllabi, certification, process alignment and IT systems), and it is argued that this should form the agenda for a series of future research projects.

As a final comment, it is important to remember that coordination does not guarantee success in all situations because, as Heaslip (2012) observes, organisations may face coordination challenges such as those reflecting cultural and structural differences. Furthermore, as Clarke (2013) cogently points out, a scarcity of funding makes effective allocation of resources critical. Consequently, coordination structures must be neither unnecessarily large, nor unnecessarily detract funding and time from the delivery of actual programming 'for the purpose of meeting the end beneficiary's requirements' (Thomas and Mizushima, 2005, p. 60).

\section{Correspondence}

Peter Tatham

Room G42_5.18; Griffith Business School; Gold Coast

QLD 4222; Australia

Telephone: 00617555 28490; Fax00 61755529206

e-mail: p.tatham@griffith.edu.au. 


\section{References}

Aitken, P. et al. (2012) 'Leadership and the use of standards by Australian disaster medical assistance teams: results of a national survey of team members'. Prehospital and Disaster Medicine. 27(2), pp. 142-147.

Akhtar, P., N.E. Marr and E.V. Garnevska (2012) 'Coordination in humanitarian relief chains: chain coordinators'. Journal of Humanitarian Logistics and Supply Chain Management. 2(1), pp. 85-103.

Austin, L. and G. O'Neil (2013) The Joint Standards Initiative Global Stakeholder Consultation Report. Joint Standards Initiative, Geneva. http://pool.fruitycms.com/humanitarianstandards/News/FINAL-JSI-StakeholderConsultation-Report.pdf (accessed 26 March 2015).

Berlin, J.M. and E.D. Carlström (2011) 'Why is collaboration minimised at the accident scene?' Disaster Prevention and Management. 20(2), pp. 159-171.

Clarke, J.N. (2013) 'Transitional coordination in Sudan (2006-08): lessons from the United Nations Resident Coordinator's Office'. Disasters. 37(3), pp. 420-441.

Day, J.M., S.A. Melnyk, P.D. Larson and E.W. Davis (2012) 'Humanitarian and Disaster Relief Supply Chains: A Matter of Life and Death'. Journal of Supply Chain Management. 48(2), pp. 21-36.

de Leeuw, S., L.R. Kopczak and M. Blansjaar (2010) 'What really matters in locating shared humanitarian stockpile: evidence from the WASH cluster'. In the proceedings of 11th IFIP WG 5.5 Working Conference on Virtual Enterprises, PRO-VE 2010, St. Etienne, France, October 11-13, 2010.

.pp. 166-172.

Dolinskaya, I.S., Z.S. Shi, K.R. Smilowitz and M. Ross (2011) 'Decentralized approaches to logistics coordination'. In T. Doolen and E. Van Aken (eds.) Humanitarian Relief Proceedings of the 2011 Industrial Engineering Research 
Conference.

Available

at:

http://www.google.fi/url?sa=t\&rct=j\&q=\&esrc=s\&source=web\&cd=7\&ved=0CFQQ

FjAG\&url=http\%3A\%2F\%2Fhl.mccormick.northwestern.edu\%2Fpublications\%2FIE

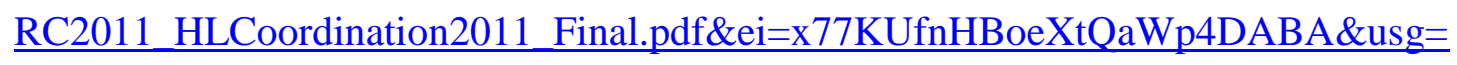
AFQjCNEZPI36K1fcw8eDVInCczYPZlxwKw\&sig2=GFyrROO0uOb4ikV811RHaA (accessed 26 March 2015).

FMTWG (Foreign Medical Team Working Group) (2013) Registration and Coordination of Foreign Medical Teams Responding to Sudden Onset Disasters: The Way Forward. World Health Organization, Geneva. http://www.who.int/entity/hac/global_health_cluster/fmt_way_forward_5may13.pdf (accessed 26 March 2015).

Fritz Institute (2012) Humanitarian Logistics Conference 2012: The Changing Face of Logistics within the Humanitarian Sector. Fritz Institute, San Francisco, CA. http://www.fritzinstitute.org/prgSC-HLC2012-proceedings.htm (accessed 26 March 2015).

Gattorna, J. (2010) Dynamic Supply Chains. Second edition. FT Prentice Hall, Harlow.

GDACS (2013) The Global Disaster Alert and Coordination System. UN OCHA, Geneva. http://portal.gdacs.org/about (accessed 30 Mar 2015).

GHC (Global Health Cluster) (2013) Global Health Cluster Partners. World Health Organization, Geneva. http://www.who.int/hac/global_health_cluster/about/partners/en/index.html (accessed 26 March 2015).

Glad, M. (2011) A Partnership at Risk? The UN-NGO Relationship in Light of UN Integration. Norwegian Refugee Oslo. http://www.nrc.no/arch/img.aspx?file_id=9175273\&ext=.pdf (accessed 30 March 2015). 
Heaslip, G. (2012) 'Challenges of civil military cooperation/coordination in humanitarian relief'. In G. Kovács and K. Spens (eds.) Relief Supply Chain Management for Disasters, Humanitarian Aid and Emergency Logistics. IGI Global, Hershey, PA.

IASC (UN Inter Agency Standing Committee) (2011) Coordination and Registration of Providers of Foreign Medical Teams in The Humanitarian Response to SuddenOnset Disasters: A Health Cluster Concept Paper. UN IASC, Geneva. http://www.who.int/hac/global_health_cluster/about/policy_strategy/fmt_concept_pap er_27_May.pdf (accessed 26 March 2015).

IASC (UN Inter Agency Standing Committee) (2012) Reference Module for Cluster Coordination at the Country Level. UN IASC, Geneva. https://www.humanitarianresponse.info/system/files/documents/files/iasccoordination-reference\%20module-en_0.pdf (accessed 30 March 2015).

INSARAG (2012) INSARAG Guidelines, 2012 Edition. INSARAG, UN OCHA, Geneva. $\quad$ www.insarag.org/images/stories/INSARAG_Guidelines-2012_ENG_Read_version.pdf (accessed 26 March 2015).

Jahre, M. and L-M. Jensen (2010) 'Coordination in humanitarian logistics through clusters'. International Journal of Physical Distribution and Logistics Management. 40(8/9), pp. 657-674.

Kapucu, N., T. Arslan and F. Demiroz (2010) 'Collaborative emergency management and national emergency management network'. Disaster Prevention and Management. 19(4), pp. 452-468.

Kovács, G. and K.M. Spens (2011) 'Trends and developments in humanitarian logistics: a gap analysis'. International Journal of Physical Logistics and Distribution Management. 40(1), pp. 32-45.

Kovács, G. and P.H. Tatham (2009) 'Responding to disruptions in the supply network: from dormant to action'. Journal of Business Logistics. 30(2), pp. 215-229. 
Kunz, N. and G. Reiner (2012) 'A meta-analysis of humanitarian logistics research'. Journal of Humanitarian Logistics and Supply Chain Management. 2(2), pp. 116147.

Logistics Cluster (2010) 'Haiti Logistics Cluster: operational overview'. ReliefWeb, UN OCHA, Geneva.

http://reliefweb.int/sites/reliefweb.int/files/resources/308BB4CE6B88DEAB492576B B0018434E-Full_Report.pdf (accessed 26 March 2015).

Majewski, B. et al. (2012) Joint Evaluation of the Global Logistics Cluster Vol. 1: Full Report. World Food Programme, UNICEF and Government of the Netherlands. http://documents.wfp.org/stellent/groups/public/documents/reports/wfp251775.pdf (accessed 26 March 2015).

Norton, I. et al. (2013) ' Classification and Minimum Standards for Foreign Medical Teams in Sudden Onset Disasters'. Global Health Cluster, World Health Organization, Geneva. http://www.who.int/hac/global_health_cluster/fmt_guidelines_september2013.pdf(acc essed 30 March 2015).

Oloruntoba, R. and R. Gray (2009) 'Customer service in emergency relief chains'. International Journal of Physical Distribution and Logistics Management. 39(6), pp. 486-505.

Salmon, P., N. Stanton, D. Jenkins and G. Walker (2011) 'Coordination during multiagency emergency response: issues and solutions'. Disaster Prevention and Management. 20(2), pp. 140-158.

SARAID (Search and Rescue in Disasters) (2010) SARAID News. Norwich, UK. http://saraid.tumblr.com/page/4 (accessed 26 March 2015).

SCHR (Steering Committee for Humanitarian Response) (2013) Overview of the SCHR Certification Project. SCHR, Geneva. 
http://www.schr.info/assets/uploads/docs/SCHR-Certification-Project-Overview06Feb2013.pdf (accessed 30 March 2015).

Smith, D. And D. Elliott (2007) 'Exploring the barriers to learning from crisis'. Management Learning. 38(5), pp. 519-538.

Stock, J.R. (1997) 'Applying theories from other disciplines to logistics'. International Journal of Physical Distribution and Logistics Management. 27(9/10), pp. 515-539.

Tatham, P.H. and S.J. Pettit (2010) 'Transforming humanitarian logistics: the journey to supply network management'. International Journal of Physical Distribution and Logistics Management. 40(8/9), pp. 609-622.

Tatham, P.H. and K. Hughes (2011) 'Humanitarian logistics metrics: where we are, and how we might improve'. In M.G. Christopher and P.H. Tatham (eds.) Humanitarian Logistics: Meeting the Challenge of Preparing for and Responding to Disasters. Kogan Page, London, pp. 65-84.

Tatham, P.H., K.M. Spens, G. Kovács and J. Payne (2013) 'A common humanitarian logistics picture: development issues and challenges'. In the proceedings of the NOFOMA conference. 3-5 June. Gothenburg, Germany.

Thomas, A. and L. Kopczak (2005) From Logistics to Supply Chain Management: The Path Forward to the Humanitarian Sector. Fritz Institute, San Francisco, CA. http://www.fritzinstitute.org/pdfs/whitepaper/fromlogisticsto.pdf (accessed 26 March 2015).

Thomas, A. and M. Mizushima (2005) 'Logistics training: necessity or luxury?' Forced Migration Review. 22. pp. 60-61. 
von Schreeb, J., L. Riddez, H. Samnegard and H. Rosling (2008) 'Foreign field hospitals in the recent sudden-onset disasters in Iran, Haiti, Indonesia, and Pakistan'. Prehospital and Disaster Medicine. 23(2), pp. 144-151.

Völz, C. (2005) 'Humanitarian coordination in Indonesia: an NGO viewpoint'. Forced Migration Review. Special Issue, 26-27 July, pp. 26-28.

WFP (World Food Programme) (2012) WFP Logistics in 2012: Changing the Way We Deliver.

WFP, Rome.

http://documents.wfp.org/stellent/groups/public/documents/communications/wfp2576 80.pdf (accessed 26 March 2015). 